\section{Statement on publishing clinical trials in indian biomedical journals}

The registration of clinical trials will help improve "reliability of data generated, help clinicians interpret research, minimize duplication of trials, and prevent exposure of volunteers to potential risks'. The Clinical Trial Registry India (CTRI) (www.ctri.in) hosted at the National Institute of Medical Statistics (NIMS), Indian Council of Medical Research (ICMR), New Delhi, was formally launched on July 20,2007. This is a free online registry of clinical trials with the aim to encourage all clinical trials conducted in India to be prospectively registered before the enrollment of the first participant and to disclose details of the 20 mandatory items of the WHO International Clinical Trials Registry Platform (ICTRP) dataset and a few additional items ${ }^{2}$. Thus, the CTRI becomes a WHO's ICTRP and ICMJE compliant Primary Register for India. Clinical trial has been defined by the ICMJE ${ }^{3}$.

Within about three months of its launch the response received has been overwhelming with over 90 clinical trials already registered. But registration of trials is just a beginning. Active steps are on to sensitize researchers who actually conduct trials, funding agencies, ethics committee members, pharmaceutical companies,, health professionals and medical journal editors on the need to register all trials that need registration. The WHO's ICTRP and ICMJE have drawn up clear guidelines on these issues ${ }^{4 " *}$. However, only prospectively registered clinical trials will be considered for publication.

While participants of clinical trials volunteer with an altruistic motive, it is too well known that still all is not well in experiments involving human subjects ${ }^{7}$. Clearly, there have been reports that trials have failed in their objective to carry out experiments fairly, report honestly and follow the ethical principles in India and abroad 8 There have been several instances of selective reporting or not reporting at all depending upon the outcome of the trial and when financial interests are at stake. Despite best efforts to ensure transparency and honesty, most initiatives to discourage the conduct of unethical trials have largely been unsuccessful.

Attempts to regulate clinical trials through system of record keeping at a public registry which would provide access to data on trials being carried out have not been very successful as trial registration is voluntary and there is reluctance of pharma companies to disclose data. As a step to ensure complete awareness of trial details, the ICMJE proposed comprehensive registration for clinical trials submitted for publication for the 12 member journals [Annals of Internal Medicine. British Medical Journal. Canadian Medical Association Journal, Croatian Medical Journal, Journal of the American Medical Association, The Dutch Medical Journal (Nederlands Tijdschrift voor Geneeskunde), New England Journal of Medicine, New Zealand Medical Journal, The Lancet, The Medical Journal of Australia, Tidsskrift for Den Norske Laegeforening, Journal of the Danish Medical Association (Ugeskrift for Laeger)] $]^{3}$. Commencing July 2005, these journals have made registration of trials in a public registry mandatory for consideration of publication. The ICMJE did not indicate a particular registry but any one that meets a set of minimum data.

With this background, the CTRI in association with the Indian Journal of Medical Research (IJMR) organized a meeting of editors of Indian biomedical journals to evolve a policy to be followed for publication of clinical trials in Indian biomedical journals. The meeting held at the ICMR on October 9, 2007, was attended by 12 editors of Indian biomedical journals. It was unanimously decided that the editors have the responsibility to promote the registration of all clinical trials being conducted in India and to urge researchers to register their trials within a stipulated time, to make the clinical trial data transparent and to enable results to be published in good journals.

On behalf of all biomedical journals published from India, we urge to all those who are either conducting and/or planning to conduct clinical trials involving human subjects, to register their trials in CTRI or in any primary clinical trial register. From January 2010 onwards, we will consider publication of a trial only if it has been registered prospectively if started in or after June 2008; trials undertaken before June 2008 need to be registered retrospectively.

K. Satyanarayana, Anju Sharma
Indian Journal of Medical Research
Purvish Parikh
Indian Journal of Cancer
V. K. Vijayan
Indian Journal of Chest
Diseases and Allied Sciences
D. K. Sahu
Indian Journal of Medical Sciences




Barun K. Nayak
Indian Journal of Ophthalmology
R K. Gulati
Indian Journal of Pediatrics
Mahendra N. Parikh
Journal of Obstetrics and Gynecology of India
Prati Pal Singh
Journal of Parasitic Diseases
S.B. Bavdekar
Journal of Postgraduate Medicine
U. Sreehari
Journal of Vector Borne Diseases
Peush Sahni
National Medical Journal of India
For Correspondence:
kanikaram_s@yahoo. com

Barun K. Nayak

R K. Gulati

\section{References}

1. Satyanarayana K, Sharma A, Ganguly NK. Indian registry for clinical trials. Indian J Med Res 2006; 123: 587-90.

2. Clinical Trials Registry - India, National Institute of Medical Statistics (ICMR). Available at http://www.ciri.in/ Clinicaltrials/trials_Jsp/index.jsp.

3. Laine C, Horton R, De Angelis CD, Drazen JM, Frizelle FA, Godlee $\mathrm{F}$, el al. Clinical trial registration : looking back and moving ahead. Available at http://www.icmje.org/ clin_trial07.pdf.

4. World Health organi/ation, International Clinical Trials

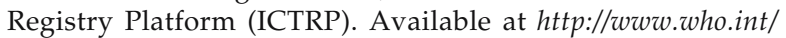
ictrp/en/.

5. De Angelis C D, Drazen JM, Frizelle FA, Haug C, Hoey J, Horten $\mathrm{R}$, et al. Clinical trial registration. A statement from the International Committee of Medical Journal Editors. JAMA 2004; 292: 1363-64.

6. De Angelis C D, Dra/en JM, Krizelle FA, Haug C, Hoey J, Morten R, el al. International Committee of Medical Journal Editors (ICMJE), Is this clinical trial fully registered? A statement from the International Committee of Medical Journal Editors. Available at $h t t p: / / w w \backslash v$.icmje.org/clin_trialnp.htm.

7. Dickersin K, Rennie D. Registering clinical trials. JAMA 2003; 290: 516-23.

8. Mudur G. India plans to audit clinical trials. BMJ2QQ5; 33J : 1044.

\section{Beginning January 2010 the Indian Journal of Thoracic and Cardiovascular Surgery will accept manuscripts for} publication only if they are registered in a clinical registry. 